\title{
Listening Past the Lies that Make Us Sick: A Voice-Centered Analysis of Strength and Depression among Black Women
}

\author{
Tamara Beauboeuf-Lafontant
}

Published online: 24 September 2008

(C) Springer Science + Business Media, LLC 2008

\begin{abstract}
An emerging feminist paradigm likens depression to silencing, as women disconnect from important aspects of their realities in an attempt to meet cultural standards of feminine goodness. While offering a provocative re-evaluation of hegemonic feminine norms and depressive episodes, little in this literature explores connections between silencing and depression within other, non-white constructions of feminine goodness. Employing a voice-centered method that illuminates areas of conflict between cultural scripts and individual meaning making, I forward that being strong is both the depiction of Black feminine goodness and an important contributor to depressive episodes. Drawing on interview data from a nonclinical sample of 58 Black women, I illustrate three depressionrelevant aspects of Black women's gendered experiences: the promotion of their stoicism, silence, and selflessness through the prevailing discourse of the "strong Black woman"; the active suppression of discourse-discrepant realities which the women associate with depressive experiences; and the psychological healing attendant on supplanting this discourse with experience-based knowledge of their social realities. Voice-centeredness, I conclude, brings a needed sensitivity to depression as a racialized and gendered experience of distress tied to the normative conditions of Black women's lives.
\end{abstract}

Keywords Depression $\cdot$ Silencing $\cdot$ Voice $\cdot$ Strength $\cdot$ Black women

\section{The silencing paradigm: A feminist understanding of depression}

Many women in our society live in an untenable position, wedged between sociocultural expectations and their own human growth potential.... Yet women thirst to be more than the roles and behaviors that are ascribed to them, and therein lies the trap of depression. (Schreiber 1996, p. 490)

To explain the fact that women are overwhelmingly the victims of depression, some feminist theorists and researchers have argued that its incidence is tied to normative

T. Beauboeuf-Lafontant $(\bowtie)$

Department of Education Studies, DePauw University, 7 Asbury Hall, Greencastle, IN 46135, USA

e-mail: tbeauboeuf@depauw.edu 
femininity, rather than to aspects of women's biological makeup as is commonly asserted in medical and lay understandings of the distress (Jack 1991, 1999a, b; Schreiber 1998, 2001; Schreiber and Hartrick 2002; Stoppard 2000). While not denying a biological contribution to depression, researchers in what I am calling the silencing paradigm conceptualize depression as a crisis embedded in the everyday inequitable social relations (interpersonal and structural) that surround and define a woman's social existence (Jack 1991; Laitinen and Ettore 2004; Mauthner 2002; Stoppard and Gammell 2003). Firmly rooted in qualitative research that seeks to develop richly contextualized understandings of human experience, such research reveals a disconnect between medical etiologies and women's accounts and embodied knowledge of depression.

Distinctive about work in the silencing paradigm is that inquiry begins from the standpoint of women - that is, the talk and "actualities of people's lives as they experience them" (Smith 1996, p. 172). Most provocatively, the silencing paradigm refutes the conceptualization of depression as a unique and pathological state, as portrayed in the medical literature, and instead depicts it as a process and a continuum with deep roots in what are largely considered "normative" conditions of femininity and representations of feminine goodness. Turning to women as guides - in part to remedy the lack of women's perspectives on their distress in the scholarly literature (Schreiber and Hartrick 2002; Stoppard 2000) - the silencing paradigm has generated novel insights into the onset, experience of, and recovery from depression.

Much of femininity in terms of beauty regimes, economic and political disenfranchisement, and the biological arguments deployed to burden women with unremunerated reproductive work seeks to render them into 'docile bodies' (Foucault 1977) and compliant minds. Such paring down and reduction of their subjectivity to those dictates attempts to reduce the possibility of women's resistance to these arbitrary and unjust configurations of power. Working from this understanding of subjectivity and control, and applying it to the social circumstances of women, the silencing paradigm maintains that much of depression emanates directly from the conditions of womanhood. The distress lays bare an ongoing and normalized dilemma of femininity, as women struggle against the limitations - psychological, physical, economic, and relational-constitutive of feminine goodness.

More specifically, the silencing paradigm conceives of depression as a psychosocial process in which women lose and then "mourn" a self that has become "submerged, excluded, or weakened" (Jack 1991, p. 30) under relationships, identities, and "normative restrictions of goodness and niceness" (Fox 1977, p. 805) that they are socialized to view as central to their social acceptance and critical to their personal welfare. The paradigm further asserts that standards of goodness are drawn from cultural discourses which, once internalized, exert a moral force that judges and condemns many of the thoughts and feelings that women register as grounded in their actual experiences (Jack 1999a, p. 223). The onset of depressive episodes, then, is essentially a period in which women become aware of a fracture (Schreiber 1998) resulting from doubting and repressing private thoughts that are at odds with the forms of femininity that they are pressured to take on in order to be considered good women (Jack 2003). Within the silencing paradigm, depression arises from the dilemma of how to create a life worth living given the "absence of viable alternatives to the identities of wife, mother and housewife, coupled with the lack of social value attached to women's work in the home" (Stoppard 2000, p. 109). It is this dilemma of femininity and the insistence that femininity must be "continually achieved and cannot be taken for granted" (Fox 1977, p. 812) which gives rise to the emotional and behavioral traits commonly associated with depression- "feelings of hopelessness and helplessness, 
depressed mood, social withdrawal, fatigue, and inability to engage in everyday activities" (Stoppard 2000, p. 213).

Within the silencing paradigm, depression is understood as a complex state of insight and crisis, cognitive awareness and compromised physiological functioning. In their retrospective accounts, women often describe the existence of two distinct selves, one preceding and the other following the depressive episodes. The first is relatively unaware or profoundly afraid of the costs of alternatives to feminine goodness in their lives. Although "vaguely dissatisfied and...living within quite narrowed boundaries of life," this self views meeting others' expectations as the primary route to maintaining the social standing of a good woman (Schreiber 1996, p. 475). During the depressive episode, women question the normative assumptions about their femininity and general existence as a subordinated group. In this process of "cluing in," a woman "mak[es] connections" between not only what she knows cognitively, but also what she feels on a "gut level" (Schreiber 1996, p. 484). Such emotional knowing leads to the realization that parts of herself have been "missing" from her earlier identity. Following this insight, depressed women face a choice- to move toward recovery which requires a reintegration of those aspects of self that fall outside the narrow confines of being a good, culturally valued woman, or avoiding this process of personal change and social critique by now willfully suppressing what they, on a deeper level, know to be true and in need of attention.

Full recovery from depression involves uniting a cognitive awareness with subjective knowing, and finding ways to examine whether the external messages women hear are accurate, useful, and inclusive of what they feel and know through experience. Making such connections and resisting continued dissociation requires that women question received wisdom in its cultural constructions of "good" womanhood, which are often predicated on subordinating their needs as daughters, wives, mothers, community members, employees, and citizens through an ethic of other-centeredness (LaFrance and Stoppard 2007). As a result, women pursuing recovery refuse to continue concealing their realities in order to protect an ideology of femininity. Instead, they interrogate standards of feminine goodness whose "moral authority... [over them] begins to crumble" (Jack 1991, p. 196; emphasis in original), and they come to see that such conventional beliefs are, in fact, lies that have made them sick (Gilligan [1982] 1993, p. xxvi).

Afraid of what they will lose - the regard and praise of others; connection, albeit tenuous and duplicitous, to loved ones; a belief in particular ideologies-women may resort to the emotionally laborious process of "staying clued out." Such women settle for the familiarity of a "pseudo-recovery," or an ongoing state of disconnection and self-sacrifice to garner their acceptance by others (Schreiber 1996). Continuing to live on two disconnected levels, having thoughts, particularly those prescribed by the ideologies of their social context, that are at odds with their embodied experiences, these women retain an inner/outer split. Doing so, they undertake an intensified suppression of their needs to promote a façade of competence and contentment - a strategy which upholds and protects cultural ideals of femininity at a cost to their own needs and overall long-term wellness (LaFrance and Stoppard 2007; Mauthner 2002, pp. 13-14).

Despite the silencing paradigms' insights into women's depression, little in this work has challenged a prevailing notion of the distress as a white women's illness (Amankwaa 2003a, b; see Schreiber et al 1998, 2000 for exceptions). Nor has this developing body of work addressed an implicit corollary to this belief - that Black women, as "strong" women, are culturally protected from depression (Edge and Rogers 2005). The need for a broader conceptualization of silencing within femininities is evident given the consistent finding in epidemiological studies that racial minority status and poverty are associated with elevated 
rates of depression among women, particularly during their childbearing and childrearing years (Seifert et al 2000). Earning less than white women, Black women are also more likely to raise children as single parents and to be poor (Williams 2005). Such disparate structural conditions are embedded in the findings that Black women develop clinical depression at rates comparable to white women, and exhibit greater levels of subclinical distress than most other race-gender groups (Brown and Keith 2003). Approximately onequarter of American women will experience depression in their lives, and about $9 \%$ are depressed at any time. Although $20 \%$ of depressed Americans receive treatment, as few as $7 \%$ of Black women do so (Mitchell and Herring 1998, p. 4).

Further insisting on the need for an understanding of depression as racialized and gendered is the emergence over the last decade of a growing autobiographical and clinical literature focused on the experiences of depressed Black women. Significant about this experiential and qualitative literature is its highlighting of a particular approach to femininity - being strong — as a culturally distinctive aspect of Black women's experiences of the distress (Boyd 1998; Amankwaa 2003b; Danquah 1998; Jones and Shorter-Gooden 2003; Martin 2002; Mitchell and Herring 1998; Schreiber et al. 1998, 2000). Despite the persistence of this association of strength with depression, little in this literature evaluates whether being strong is a helpful or problematic aspect of Black women's experiences of emotional distress. Moreover, left unconsidered is whether strength as a construction of feminine goodness could itself place black women at risk for depression.

Although depression is often linked to malingering or lack of will, in the Black community it is overwhelmingly viewed as a "weakness of the lowest kind" (Boyd 1998, p. 5). Depression is anathema to African Americans because it violates what bell hooks (1993, p. 70) describes as an intraculturally held "claim to superiority... [over] "silly" white people...that we do not suffer mental illness." In response to such cultural beliefs, Black women's depression is often masked by their behavior. Voicing profound concerns for the often hidden and overwrought worlds of depressed Black women, writer Charisse Jones and psychologist Kumea Shorter-Gooden (2003, pp. 125-126) maintain that the distress "has a somewhat distinctive look":

If you're trying to identify depression in Black women, one of the first things to look for is a woman who is working very hard and seems disconnected from her own needs. She may be busy around the clock, constantly on the go, unable to relax, and often compromising her sleep for household, child-care, and job tasks that she feels impelled to take care of. Not taking the time to tend to herself makes her more vulnerable to depression. Or her busyness may be a way to keep her mind off the feelings of sadness that have already arisen.

In puzzling over the disconnect between the risk of depression Black women experience and the perception of them as shielded from the distress, I began to consider whether the concept of the "strong Black woman" might itself play a decisive role in both the etiology of depression and the perception of Black women's invulnerability. Support for this line of reasoning comes from Black feminist scholarship.

\section{Good, strong black women: Empirical reality or social ruse?}

Over the last 30 years, Black feminists have scrutinized not simply the material but the ideological aspects of Black women's subordination. Developing an intersectional analysis to examine the workings of racism, classism, compulsory heterosexuality, and sexism in 
Black women's lives, theorists such as bell hooks (1993), Barbara Smith ([1983] 2000), and Michelle Wallace (1990) have raised questions about the normative depiction of Black women as strong. Largely based on personal accounts and observations, their critiques have suggested that strength is not an objective description of Black women, but a prescriptive discourse embedded in both racist and sexist characterizations of Black women as laborers for others.

Whether portrayed as subhuman, mule-like mammies or as superhuman, inordinately capable mothers, strong Black women are accorded little attention to their existence outside of such extensive ongoing and non-negotiable service. As a result, Black feminists have regarded strength as a "myth" (Wallace 1990) imposed upon Black women, and likened strong Black women to "female Atlases" (Gillespie 1984) and ever-working and everaccommodating "Sisterellas" relegated to lives of drudgery and exploitation in and outside of their communities (Jones and Shorter-Gooden 2003). This culturally dominant form of femininity has also been critiqued for being simply yet tellingly the definition of "good women" (Mitchell and Herring 1998; Thompkins 2004) who are expected to engage in caretaking and doing for others, even at high cost to self. That strength is the prevailing definition of respectable Black femininity is further indicated in the common childrearing practice of "armoring" of Black girls within families. As a result, Black women learn to evidence their resistance to social inequality through the capacity to endure struggles with a stiff upper lip (Bell and Nkomo 1998; see also Scott 1991; Ward 1996). The embrace of strength as a normative construction of goodness is also suggested by the defensiveness found among Black women regarding the suggestion that their strength is anything but an affirming and positively defining quality of their womanhood (Boyd 1998; Amankwaa 2003a; Mitchell and Herring 1998).

\section{Voice-centeredness: A feminist methodology}

Voice-centered scholarship examines the interplay of societal representations of gender with the actual experiences of individuals. The concept of voice powerfully emerged in the social sciences with Carol Gilligan's 1982 publication of In a Different Voice: Psychological Theory and Women's Development, a text which opened the door to listening carefully to interview data to distinguish different reference points for meaning making that could be aligned with as well as resistant to dominant forms of femininity. As Dorothy Smith (1987, p. 107) argues, to focus inquiry on women's voices rather than prevailing social discourses is subversive act of "creat[ing] the space for an absent subject." It is also an intentional attempt to access the "subjugated knowledge" (Collins 2000) which oppressed groups and individuals create in order to sustain themselves in situations of inequity.

Focused largely on the overlooked and distorted experiences of women, voice-centered research has sought to access and understand a central dynamic: the distinctions between cultural understandings of women or how they are supposed to think, feel, and act, and the perspectives or voices of individual women expressing thoughts and feelings that are relatively "free from second thoughts and instant revision" (Gilligan 2003, p. 25). Voicecentered researchers point to the necessity of listening for such possible subject positions or voices in ways that distinguish them from the discourses or socio-cultural frameworks "that overrid[e] what we know and feel and experience, that tel[1] us what we should see and feel and know" (Gilligan 2003, p. 9).

In voice-centered research, attention is placed on the particular ways in which an individual speaks from an experienced-based standpoint that marks its proximity to and 
distance from cultural narratives. Thus, voices are subject positions identifiable by their relative obedience or resistance to a particular discourse. However, within a recognized situation of social inequality, voice is "more than an academic shorthand for a person's point of view"; it is also a poignant reflection of the experiences of empowerment and powerlessness that pervade people's lives as they attempt to speak up and out, are silenced, and resist demeaning characterizations (Belenky et al. 1997, p. 18). As a result, voices can be at odds with actual behavior. Speaking of her voice-centered (rather than discoursefocused) work with teenage girls, Lyn Mikel Brown (1998, p. 36) highlights the complexity of their subjectivity:

They struggle with, critique, and resist what passes as feminine expression and behavior, even as they come to speak through culturally sanctioned, patriarchal voices of femininity, and publicly perform, at times even judge other girls, along the same narrow standards.

Scrutinizing voices and discourses in the speech of interviewees places in relief the uneven and incomplete processes of socialization, as well as the variable terrain of our existence as human beings - both of which often escape notice when the investigative focus is only on behavior or when assessments view speech as flat, self-evident utterances. Furthermore, while privileging the standpoint of the oppressed, voice-centeredness builds analyses by attending to the meaning-making of individuals. Thus, it retains a sensitivity to the diversity of responses evident as people engage with the discourses and material conditions of disenfranchisement.

\section{Methods}

In order to empirically examine both the construction of good Black womanhood as "being strong" and its possible contributions to depression, I undertook a voice-centered interview study. During the period of 2001-2006, I recruited a non-clinical, convenience sample of 58 African American women through flyers, social and professional networks, and word of mouth for a study of notions of womanhood and beauty. ${ }^{1}$ The women who spoke with me included non-traditional college students enrolled in an open-admissions university and an urban women's college, members of a loose friendship circle in a government agency, and individuals I encountered in my life as a Black woman and an academic. Whether recruited through posters, key informants, or personal invitation, most of the women predicated their agreement to participate on having knowledge of me. That is, their willingness to reveal aspects of their lives hinged on knowing who I was - that I was an acquaintance of someone they trusted, a professor they had heard about, someone they had met personally, or that I, too, was a Black woman. Within the interviews, many women stated that the opportunity to focus on their womanhood was generally a novel and fruitful experience, one which they described as cathartic in terms of letting them speak without judgment about aspects of what they knew and felt.

My interviews with these women were largely individual, but on occasion were undertaken in pairs or a small group. Lasting from 30 minutes to 3 hours, they varied in

\footnotetext{
${ }^{1}$ The broad focus of the study reflected several factors: my initial interest in womanhood as manifested in women's conceptions of feminine goodness and beauty; my desire to evaluate whether being strong emerged spontaneously in women's descriptions of womanhood; and the emergence of my concern regarding depression as a potential embodiment of strength as feminine goodness. The paper draws primarily on the last two dimensions of the study.
} 
terms not only of length, but intensity and detail. Adopting the voice-centered feminist practice of seeing the women as my teachers, as those who held the keys to understanding strength, I sought to be a sympathetic witness to their accounts and to listen for multiple standpoints in their narratives of self and society. I opened interviews with a general statement of my concerns about the paucity of research detailing womanhood and beauty from the perspectives of Black women, and an acknowledgement that I was seeking their assistance to gain insight into the lived experiences and actual perspectives of Black women. I then asked the women to discuss the salience of three characteristics they associated with being a Black woman. The majority of interview time was spent probing and asking follow up questions to acquire a more nuanced sense of how and why the women saw their womanhood in particular ways. In addition to ascertaining their views on womanhood, I also sought their viewpoints on two additional areas of concern - the concept of "the strong Black woman" and the existence and experiential realities of depression among Black women. In both instances, I was frank about my position as a Black woman and researcher who was trying to determine the relevance of these experiences given the absence of substantive attention to them in the social science literature.

The women interviewed ranged in age from 19 to 67, with a mean of 35.6 years. Although the sample is not representative of Black women as a whole and is skewed toward those with some college attendance, a majority of the women were either working-class $(15$, or $26 \%$ ) or could be usefully classified as "newly middle class" (26, or 45\%) (Hill 2005). For the latter group, the women's social mobility was recent, individual, and achieved rather than inherited. Furthermore, although largely employed in majority-white settings, they maintained deep interpersonal and material ties to Black working-class family and friends (Cole and Omari 2003). Straddling two cultural and social classes gave them a particular "outsider-within" (Collins 2000) standpoint that promoted their viewing of womanhood in relational rather than absolute terms. Thus, as they articulated both the continuities and differences that marked their lives and those of the women with whom they interacted, the interviewees brought to the project a wider context of femininities than might be suggested by their age or class status.

\section{Using a voice-centered tool: The Listening Guide}

Out of voice-centered concerns about women's relationships to a society predicated on their subordination has emerged a particular empirical tool, the Listening Guide. Described as a feminist, literary, and clinical method (Brown and Gilligan 1992), the Listening Guide has three distinctive qualities: It acknowledges the presence and pervasiveness of sexism constituted within race and class inequities; it views utterances as multi-layered texts with both manifest and more latent content; and it hinges on the willingness of researchers to listen for what a woman really believes and feels beyond cultural prescription and normsthat is, those narratives beyond the constraints of acceptability (Anderson and Jack 1991, p. 11). This feminist foundation of the method can be seen in the uses of the Listening Guide for research that has critically examined aspects of gender socialization, such as adolescent female sexuality (Tolman 2002); anger among girls (Brown 1998) and women (Jack 1999c); girls' relationships with each other and adult women (Taylor, Gilligan, and Sullivan 1996); boys' understanding of their same-sex friendships (Chu 2005); and women's experiences of depression (Jack 1991). The Listening Guide accomplishes its focus on the less evident and socially disruptive aspects of speech - "the coded or indirect language of girls and women, especially regarding topics...that [they] are not supposed to speak of" 
(Tolman 1994, p. 326) - by directing researchers through rounds of guided readings of transcribed interviews.

Although developed and primarily utilized to analyze the psychosocial realities of white, middle-class women's experiences of gender subordination, there is little in the Guide to preclude its use to empirically investigate the voices of other groups as well as the specific gender discourses through which they are perceived. Tensions between discourses and voices, between normalized representations and subjectivity, are central features of contemporary configurations of power in a race-, class-, and gender-stratified society. My own use of the Guide begins with the premise that the shared meanings and ideological interests of discourses largely structure the kinds of narratives about self and other told. Thus, instead of assuming hegemonic femininity to be present in interview data, I looked for evidence of a particular construction of femininity-in this case, strong Black womanhood-and evaluated the ways in which it affected the thought and behavior of the women I interviewed. In the next section, I illustrate my use of the Listening Guide, highlighting the ways in which it prompted me to read the transcripts and to come to particular insights about strength, its silencing qualities, and its relationship to depression in the lives of Black women.

\section{Listening for and past a discourse of strength}

To understand strength as a discourse of femininity, I focused on the actual transcript sections in which the women discussed the meaning of being a strong Black woman, and the repeated themes and metaphors that the women used in their descriptions. Strength was a concept that shaped the behavior and subjectivities of 43 or $74 \%$ of the 58 interviewees. From the inventory generated by this reading, I found that struggle, extensive caretaking responsibilities to others, and stoicism are critical to the demonstration of strength:

And I think that strong woman ${ }^{2}$ idea has been planted in my head, too. That you're supposed to be able to, you know, just muster through this, and, you know, make it without scarring or whatever. (29, divorced mother, bank employee)

My mom. She, she real strong.... And, my mom will work, and I think her only downfall was that she worked and she helped to take care of everybody else's kids, too.... She just, she always tried to help other people. And I think, sometimes, Black women get used by trying to help other people.... You know, it's like, Black women just think they're everybody's mother. (24, single, student)

We think that if we're not this superwoman, we kind of, we'll put the blame on ourselves, for not being able to accomplish all these things. And try to be this 24-hour woman, that, everybody, you know, society kind of makes you believe you have to be.... Whether it would be your partner, or your mother putting the, 'You know, I did it, so why can't you do it,' you know. (24, single mother, surgical assistant)

As the preceding quotes underscore, strength is a discourse replete with mandates. A strong Black woman should "muster through" all adversity "without scarring," should "always [try] to help other people," and should present herself as a capable "24-hour woman" regardless of the demands and stresses she faces. Particularly noteworthy is the open-endedness of this prescription of silent, ongoing struggle. In these and other accounts,

\footnotetext{
${ }^{2}$ For the remainder of the paper, italicized words reflect emphases in the original transcripts.
} 
there is very little, if any, sense of limits as to what can be expected of a "strong Black woman." Identifying intimate connections between strength and an "authentic" Black womanhood predicated on selflessness, and adversity, another woman states:

We're always doing it alone, and the men can't come through, and now I'm strong. But how many women whose husbands come through are strong? I'm saying the definition of strength within the Black paradigm, includes lack of self-care and lack of a partner. It's difficult to assert yourself as a married Black woman in a stable relationship, as a strong woman, unless you have an abundance of kids or something where you work two or three jobs. (32, single mother, college administrator)

In short measure, strength can introject unremitting adversity - whether due to financial strains, workplaces injustices, or relational abuses - into validating qualities of Black women's authenticity among family and peers. A single, 39-year old school teacher who has taken in others' children remarks that when people claim that a Black woman is strong, "nobody seems to understand that you are striving to stay afloat.... And I can even see it, in relationship to Black men.... The person doesn't see that, you know, you need some assistance with your load. The person's like, 'You don't need anything. I need you to take care of me." Examining these descriptions makes evident that strength is an externally defined role tellingly lacking concern for experience-based meaning making. Rendering women's subjective point of view immaterial, strength encourages them to "put the blame on ourselves" for not measuring up to the standards and circumstances seen as synonymous with Black womanhood.

\section{Reading for self and voices}

In order to further examine the concept of strength in terms of its impact on women's thinking and behavior, I re-read the identified strength sections, this time focusing on the women's talk of the self. Noted were "I" statements as well as references to the self that were less direct, such as the expectations placed on a generalized "you" or "we." I also attended to the women's use of emphases, recantations, hesitations, audible changes in tone and volume, and abrupt shifts in focus for insight into how they were positioning themselves in, outside of, and in conflict with the discourse. Looking for patterns in these verbal cues, I found that there were three distinct subject positions from which the women spoke about their experiential realities. The existence of such voices reflected the women's active and ongoing attempts to respond to persistent demands for their stoicism, othercenteredness, and silence. Reviewing these stances of the self with regard to the prescriptions of strength, I classified them as voices of accommodation, muted critique, and acknowledged vulnerability. I discuss their qualities below.

\section{Voice \#1: Accommodation}

The discourse of strength insists that struggle, selflessness, and silence are the hallmarks of Black womanhood. Following the voice of accommodation, however, reveals that for many interviewees, strength is a carefully structured performance they give in order to remain in good standing among others. The voice of accommodation emanates from the socialization of girls who learn, as one woman described, to "pick up strength." Mimicking the steadfastness of mothers and other respected women kin, girls also come to keep fears, angers, and personal needs out of view. Such accommodations are ongoing since Black women are called upon - at home, in heterosexual relationships, and in majority-white 
workplaces - to manage difficult and unfair situations because of their reputed strength. A divorced single mother attempting to balance work, school, and parenting poignantly likens the demands of the discourse of strength to "a Black Jesus girl thing." She movingly describes the labor involved in her subsequent accommodation to this role:

So, I'm supposed to figure it out, and really that's what I've been doing. I've been forcing myself to figure out how I'm doing what I'm doing. Because people expect me to be this person, you know, [that] I'm not. If I was to, say, for instance, lose my apartment. Or if I was to lose my car. Or my lights went out. My people would freak out. Because that's not supposed to [happen]. I'm too strong for that. And, you know, I have this, all this power to make things different. And I'm not supposed to suffer like other people. (29, divorced mother, bank employee)

Although unrealistic, the expectations placed on strong Black women to be ever capable and impervious to suffering determine what this woman does and shows to others. She feels under duress to be reliable, other-directed, and uncomplaining in the process. Convinced that "my people would freak out" should her needs for sympathy or assistance become known to them, this woman and many others distinguished being "strong on the outside" from "the real me. Which is, 'Phew, I am losing it."” Rather than an identity for Black women, the interviewees reveal their strength to be charade, an act, a performance of "smoke and mirrors" which is exhausting yet necessary to maintain. In their efforts to appear strong, interviewees spoke at length about wearing masks, living behind walls, and burying acutely felt, but strength-inconsistent emotions "deep down inside."

\section{Voice \#2: Muted critique}

As expressed by the voice of accommodation, in order to demonstrate strength, Black women have to keep their discrepant feelings out of view. Anger, fear, uncertainty, and need are all emotions that various women claimed were inappropriate for them to express if they were to still be recognized by their communities as acceptable and strong Black women. What I call the voice of muted critique does not affect the outward adherence of the women to showing strength, but reflects their growing awareness that following the prescriptions of strength is a faulty strategy for managing burdensome and unfair expectations and realities in their social worlds. Significantly, women spoke of "internalization" strategies - including excesses in shopping, eating, and drinking - as ways to "numb" themselves to the growing distance between their performance of strength and their subjective realities. In these ways, they maintained their "game face" of being capable, caring, and invulnerable.

The women widely acknowledged that despite talk to the contrary, Black women did experience depression and that its presence marked the lives of many women they knew. For 26 women $(66 \%$ of those affected by the strength discourse or $44 \%$ of the sample) depression was a reality they discussed in the context of their own experiences or the lives of strong women they knew. Most interviewees framed depression as a reality and risk resulting not from biochemical imbalances or traumatic life events, but from long term accommodations to strength. Furthermore, rather than a time of self-doubt or low selfesteem, depression was commonly referred to as a "breakdown" (Amankwaa 2005) or a period of psychic and physical exhaustion tied to the combined burdens of supporting others, not attending to their own needs, and repressing strength-discrepant emotions. A 35 -year old academic with working-class roots speaks of the women in her family as having a "disposition for depression." While perhaps referring to an inherited biochemical proclivity, she also clearly acknowledges the existence of an intergenerational mandate of 
strength to which all the women had adhered. She explains, "We're supposed to suck it all up and be there for our Black community, for our Black men, be the foundation of the Black church, etc., etc. But you do it all in silence, nameless, with no credit given and no appreciation of anything that we do.... I think, you know, that that takes a toll, that kind of stress, and that kind [of] 'mum's the word. Because my mother has had a nervous breakdown. My grandmother had one before her, and I think her mother had one before her."

Talk of depression is muted, in tone and in substance, because it so directly challenges the tenets of strength, the bedrock of Black women's identity. Thus, Black women's adherence and accommodation to the discourse makes it difficult for them as well as others to recognize depression in their lives. As a 40-year old married after-school director states, "Black women will not talk, will not show their depression.... Because I think they feel that they always have to be together... A Black woman will not let someone know they're depressed. They will just go through the motions of life."

In attempting to ascertain whether this woman was speaking from personal experience, I asked her a follow-up question in the first-person plural:

TB: Why is it so important that people think we're together?

Interviewee: It goes back to many, many years ago. Because we always had to stand and be the strong person. And have the inner strength, that we feel like, if we allow people to know we're breaking down, then it becomes a flaw in who we are.... I'm not a person that's able to really show when I'm hurting, depressed.

Using "we" in my question was my attempt to extend an invitation to her to speak in more personal terms. Although she responded in kind with "we," she provided few details about the "hurting" she has experienced or what for her constitutes being "depressed." As I found with other women, the use of plural pronouns such as "we" and "you" is significant for two reasons: While suggesting the commonness of depression in the women's social networks, this shared language also provides a space of relative anonymity from which to talk about experiences most had not shared with others. In the following excerpt, a 23-year old working class single mother eloquently describes the experience of depression, while her use of the pronouns "you" and "they" affords a somewhat impersonal cover for her observations and knowledge of this distress:

I think they know deep, down inside that they're incapable of just, day-by-day doing all this, and that one day, the egg is going to crack, you know. And the ball is going to drop, but they don't want to come to terms with that. They just try to eat it all up, and just wait for that to happen. And I think, just little by little, it is cracking inside of them. They just are ignoring the tell-tale signs, you know. You revert to drinking or smoking or screaming or yelling, or, you know, other things to kind of cover up what really is going on inside. And then we have this major problem. And then, trying to seek help for that is like a sign of weakness. And then they internalize that, too.... The depression just grows and grows.

Despite this woman's lack of the use of "I," her account reveals a great sensitivity to the doubled awareness of depressed women, especially in terms of their recognition of an inner world at odds with their self-presentations (Jack 1991). That this interviewee shifts from "you" and "they" to talk about how "we have this major problem" of being perceived as weak for asking for help suggests that the experience of depression she partially exposes is closer to her own life than she is willing to openly admit. Her oblique discussion of depression appears to be an artifact of strength and an impediment to directly 
acknowledging her needs, accepting or receiving help, or making wellness-promoting changes in her life. Such reluctance to owning up to depression in personal terms also reflects a common view in the African American community that depression is a moral, psychological, and personal "weakness," a "white" distress, and thus a violation of the tenets of strength and authentic Blackness (Danquah 1998; Mitchell and Herring 1998).

Although only one woman provided detail about her clinical depression, striking is the extent to which her experience of being aware of two realities and simultaneously fearing exposure as less than strong echoes those of the other women who claimed to have a general understanding of depression among Black women. As a daughter raised in a rural Black community, she was culturally obligated - by brothers and neighbors - to uncomplainingly become the sole caretaker of two dying parents. In describing the etiology of her depression, she clearly points to the experience of being silenced and engaging in selfsilencing to uphold gendered notions of dutifulness.

I can really pinpoint the time that I came here [to take care of her parents] was when I really became depressed. I did absolutely nothing for me.... I felt so, I felt so smothered.... It wasn't as if I didn't want to take care of my parents, because I did. But um, I, I also wanted help. And I expected that people would help me, and I didn't get it.

When I inquired whether she ever asked for help, this woman responded that "I didn't... because they expected that I could do it. You know, and yeah, you know, I don't like people to see me that way. Like I didn't want people to have a negative image of me or bad image of me." As with the other interviewees, she emphasizes the influence of what psychologist Dana Crowley Jack (1991) has termed the "Over-eye," an internalized voice of culture which chastises women for not adhering to standards of femininity. However, it is important to note that this woman's discussion of a censuring voice is virtually indistinguishable from other women's talk of the fears and impediments they felt to outwardly acknowledge what they know to be going on inside, what the mother quoted above calls "these outlandish things that you're feeling inside your head." Taken together, these interviewees' descriptions of strains in their lives and minds suggest much continuity in the experiences of strong and depressed Black women, as strength requires the accommodations which over time generate the fracture and loss of self experienced as depressive "breakdowns."

\section{Voice \#3: Acknowledged vulnerability}

The third voice of acknowledged vulnerability was used by a minority ( 7 or $16 \%$ ) of the women affected by the strength discourse. Unlike the voices of accommodation and muted protest, the voice of acknowledged vulnerability allows women to speak candidly about the unfair standards of behavior imposed on them and the toll of such expectations on their minds and bodies. It is the only standpoint toward strength that directly and boldly insists on wellness and balance, and draws on these basic rights and conditions of existence to interrogate the validity of the strength discourse.

Interestingly, unlike the voice of muted critique, this voice rarely speaks in the comfortable anonymity of "we," and instead forwards a decidedly experience-based "I" vantage point. Demonstrating this shift, a 36-year-old bank employee describes her current, audibly strength-critical state of mind which followed a period of involvement in abusive heterosexual relationships:

And I just got to a point where you look at it, you make so many sacrifices for people, but people continue to live the way they want to live.... I mean, you know, some 
people, granted, it's fine for them to take care of other people. But I'm more than that. And I want more than that. And sometimes, even though I have major inner conflict, because believe me, I have inner conflict, but, I just put it to the side, and I'm like, 'You [referring to God] know my heart. You know what I want. And you know what I need and what I'm trying to do.' And I just bypass it and keep going.

Characteristic of this voice, this woman provides a sustained discussion of the particulars of her life without retreating to more general and elusive "we" or "you" statements. In contrast to the voices of muted protest and accommodation, she asserts that her unique needs have a validity that she need not defend. Notably, her response to the "major inner conflict" generated by moving away from a self-sacrificing notion of strength - modeled by her mother and expected of her by members of her community and co-workers - is to appeal to her belief that "God gave me this life" which obligates her to find out "what am I going to do with it." She, like other women using this voice, replaces a need to be strong with a commitment to recognizing her full subjectivity, including her needs and vulnerabilities. In the words of the woman who spoke earlier about her clinical depression, recovery from this distress was tied not simply to valuing herself but to contesting some of the basic beliefs of strength - that Black women do not require the care, attention, respite, and support enjoyed by others. In the place of strength, a flexible, experience-consistent definition of her humanity centers her sense of self:

What really makes a human being is a balance of both, weakness and strength. Because weakness and strength affects every aspect of humanity.... So there's really not any aspect of me I can't talk about when I think of myself as being both weak and strong.... I just know that when someone describes me, I don't want [them] to just describe, you know, the perceived strength. Like I want them to talk about what made me sad, what made me happy obviously. Perhaps talk about why, why things hurt. (35, unmarried, graduate student)

The focus on being human emphasized by this voice validates much of what other women faulted the strength discourse for not allowing - "telling my feelings," "doing things for me. Just for me," and "allowing the tears to come." In contrast to the voices of accommodation and muted protest, the subject position of recognized vulnerability allows Black women to see themselves as multidimensional and developing persons with a variety of human needs, interests, and desires. For women speaking in this voice, strength has lost its moral sway over them as a discourse-driven imposition on their thoughts and behaviors. In the place of strength, such women express "ordinary courage" (Rogers 1993) or the ability to make decisions while encompassing varied aspects of their subjectivity rather than solely or exclusively relying on the external definitions and expectations of self.

\section{Concluding thoughts}

Recognizing that inequities are structured into institutions and social relationships and internalized at a psychic level, voice-centered work attempts to create research conditions and guide analytical strategies that scrutinize the presence and impact of hegemonic discourses on the lives of members of subordinated groups. Although the voice-centered method overlaps with other qualitative methods and feminist strategies for eliciting textured understandings of women's realities, it is distinctive in identifying voices or different subjective stances as an important, telling, and critical component of challenging cultural discourses. In other words, 
voice-centered research operationalizes standpoint theory concerns (Collins 2000; Smith 1987) to make explicit room for the subjectivity and the active meaning making of women whose experiences and knowledge can never be completely appreciated by a cultural or social discourse. Pushing beyond a thematic ordering of data disconnected from an interviewee's active thinking and feeling, voice-centered work reveals the self as a changing, fluid collection of voices, some compliant, others resistant to the mandates of discourses. In the constant interplay between development and experience, reflection and exposure to ideas, women can and do develop more than one 'voice' with regard to the norms in their lives. Voice-centeredness, then, provides a lens for examining, within interview data, how women do and undo gender (Deutsch 2007; West and Zimmerman 1987) on a psychological level that may or may not be visible in their behaviors.

In terms of my specific research with Black women, I find that voice-centered attention to individual meaning making amidst cultural and social norms is a helpful corrective to common representations of race as a totalizing experience that flattens out individual characteristics or other significant sources of identity. In its distinction between discourses and a range of subject positions, voice-centeredness highlights strength as a two-sided performance of being silenced and engaging in self-silencing. Strength is not a natural quality of Black women, but a "supplied state of being" (Lorde 1993) that hierarchies of race, gender, and class seek to normalize within this subordinated group. As a scripted presentation of self and not an identity, strength fosters a chasm between representation and reality, so that appearing strong is mandated by the discourse with little regard for the actual subjective experiences of Black women. The interviewees' accommodations to strength and experiences of distress reveal the existence of inner realities that are not allowed acknowledgment in strong Black women's public presentations. Similar to the discourse of white femininity, strength renders social inequality into tests of Black women's mettle. Conceptually, the discourse of strength leaves little room for recognizing states of need and duress among Black women because they emerge from the concerns of a 'self' that the discourse systematically discounts. As a result, the discourse of strength has the effect of fixing social boundaries and defending the intentional practices of racism and intraracial sexism that leave a majority of Black women struggling to achieve economic and interpersonal security in their lives.

Utilizing voice-centeredness in my work on strength has illuminated the existence of a discourse of Black femininity as well as women's varied responses to its prescriptions of selflessness, steadfastness, and silence. The method further provides an empirical base for documenting the presence of distress in the lives of women commonly viewed as impervious to emotional and physical injury.

The experience of depression among those who accommodate to strength, and the relative absence of such distress among those women who voice their discontent with strength's mandates further suggest that subscribing to the discourse negatively impacts the mental and physical wellbeing of Black women. Thus, attention to voice may provide a fruitful avenue for future study focused on how the prevalence of depression - as well as other distresses such as overeating and obesity, hypertension, diabetes found among Black women-may be the embodiment of accommodating to strength which is experienced as an imperative to constantly suppress one's desires and interests. Alternatively, subsequent research might explore the presence of these three voices of accommodation, muted protest, and recognized vulnerability in a clinical sample of Black women with histories of depression. It is in such attention to the said and unsaid, to both the discourses about and subject positions of Black women that voice-centered research has the ability to help us more completely understand our current world and envision more just formulations. 
Acknowledgments I would like to thank the anonymous reviewers and the editor, Javier Auyero, for their thoughtful and constructive feedback.

\section{References}

Amankwaa, L. C. (2003a). Postpartum depression among African-American women. Issues in Mental Health Nursing, 24, 297-316.

Amankwaa, L. C. (2003b). Postpartum depression, culture, and African-American women. Journal of Cultural Diversity, 10, 23-29.

Amankwaa, L. C. (2005). Maternal postpartum role collapse as a theory of postpartum depression. The Qualitative Report, 10, 21-38.

Anderson, K., \& Jack, D. (1991). Learning to listen: Interview techniques and analyses. In S. Berger Gluck, \& D. Patai (Eds.), Women's words: The feminist practice of oral history (pp. 11-26). New York: Routledge.

Belenky, M., McVicker, Clinchy, B., Rule Goldberger, N., \& Mattuck Tarule, J. ([1986] 1997). Women's ways of knowing: The development of self, voice, and mind. New York: Basic Books.

Bell, E. E., \& Nkomo, S. (1998). Armoring: Learning to withstand racial oppression. Journal of Comparative Family Studies, 29, 285-295.

Boyd, J. (1998). Can I get a witness?: For sisters, when the blues is more than a song. New York: Dutton.

Brown, L. (1998). Raising their voices: The politics of girls' anger. Cambridge, MA: Harvard University Press.

Brown, L., \& Gilligan, C. (1992). Meeting at the crossroads: Women's psychology and girls' development. New York: Ballantine.

Brown, D., \& Keith, V. (2003). The epidemiology of mental disorders and mental health among African American women. In D. Brown, \& V. Keith (Eds.), In and out of our right minds: The mental health of African American women (pp. 23-58). New York: Columbia.

Chu, J. (2005). Adolescent boys' friendship and peer group culture. New Directions for Child and Adolescent Development, 107, 7-22.

Cole, E., \& Omari, S. (2003). Race, class and the dilemmas of upward mobility for African Americans. Journal of Social Issues, 59, 785-802.

Collins, P. H. (2000). Black feminist thought: Knowledge, consciousness, and the politics of empowerment (2nd ed.). New York: Routledge.

Danquah, M. (1998). Willow weep for me: An African American woman's journey through depression. New York: One World.

Deutsch, F. (2007). Undoing gender. Gender \& Society, 21, 106-127.

Edge, D., \& Rogers, A. (2005). Dealing with it: Black Caribbean women's response to adversity and psychological distress associated with pregnancy, childbirth, and early motherhood. Social Science and Medicine, 61, 15-25.

Foucault, M. (1977). Discipline and punish: The birth of the prison. New York: Vintage.

Fox, G. L. (1977). 'Nice girl': Social control of women through a value construct. Signs, 2, 805-817.

Gillespie, M. (1984). The myth of the strong black woman. In A. Jaggar, \& P. Rothenberg (Eds.), Feminist frameworks: Alternative theoretical accounts of the relations between women and men (pp. 32-35). New York: McGraw-Hill.

Gilligan, C. (1993 [1982]). In a different voice: Psychological theory and women's development. Cambridge, MA: Harvard University Press.

Gilligan, C. (2003). The birth of pleasure: A new map of love. New York: Random House.

Hill, S. (2005). Black intimacies: A gender perspective on families and relationships. Walnut Creek, CA: Altamira Press.

Hooks, B. (1993). Sisters of the yam: Black women and self-recovery. Boston: South End Press.

Jack, D. C. (1991). Silencing the self: Women and depression. Cambridge, MA: Harvard.

Jack, D. C. (1999a). Silencing the self: Inner dialogues and outer realities. In T. Joiner, \& J. Coyne (Eds.), The interactional nature of depression (pp. 221-246). Washington, DC: American Psychological Association.

Jack, D. C. (1999b). Ways of listening to depressed women in qualitative research: Interview techniques and analyses. Canadian Psychology, 40, 91-101.

Jack, D. C. (1999c). Behind the mask: Destruction and creativity in women's aggression. Cambridge, MA: Harvard.

Jack, D. C. (2003). The anger of hope and the anger of despair: How anger relates to women's depression. In J. Stoppard, \& L. McMullen (Eds.), Situating sadness: Women and depression in social context (pp. 62-87). New York, NY: New York University.

Jones, C., \& Shorter-Gooden, K. (2003). Shifting: The double lives of Black women in America. New York: Harper Collins. 
LaFrance, M., \& Stoppard, J. (2007). Constructing a non-depressed self: Women's accounts of recovery from depression. Feminism \& Psychology, 16, 307-325.

Laitinen, I., \& Ettore, E. (2004). The woman and depression project: Feminist action research and guided self-help groups emerging from the Finnish women's movement. Women's Studies International Form, 27, 203-221.

Lorde, A. (1993). Uses of the erotic: The erotic as power. In Zami, Sister Outsider, Undersong (pp. 53-59). New York: Quality Paperback Book Club.

Martin, M. (2002). Saving our last nerve: The African American woman's path to mental health. Chicago: Hilton.

Mauthner, N. (2002). The darkest days of my life: Stories of postpartum depression. Cambridge, MA: Harvard.

Mitchell, A., \& Herring, K. (1998). What the blues is all about: African American women overcoming stress and depression. New York: Perigee.

Rogers, A. (1993). Voice, play, and a practice of ordinary courage in girls' and women's lives. Harvard Educational Review, 63, 265-295.

Schreiber, R. (1996). (Re)defining my self: Women's process of recovery from depression. Qualitative Health Research, 6, 469-491.

Schreiber, R. (1998). Clueing in: A guide to solving the puzzle of self for women recovering from depression. Health Care for Women International, 19, 269-288.

Schreiber, R. (2001). Wandering in the dark: Women's experiences with depression. Health Care for Women International, 22, 85-98.

Schreiber, R., \& Hartrick, G. (2002). Keeping it together: How women use the biomedical explanatory model to manage the stigma of depression. Issues in Mental Health Nursing, 23, 91-105.

Schreiber, R., Stern, P. N., \& Wilson, C. (1998). The contexts for managing depression and its stigma among Black West Indian Canadian women. Journal of Advanced Nursing, 27, 510-517.

Schreiber, R., Stern, P. N., \& Wilson, C. (2000). Being strong: How Black West-Indian Canadian women manage depression and its stigma. Journal of Nursing Scholarship, 32, 39-45.

Scott, K. (1991). The habit of surviving. New York: Ballantine.

Seifert, K., Bowman, P., Heflin, C., Danziger, S., \& Williams, D. (2000). Social and environmental predictors of maternal depression in current and recent welfare recipients. American Journal of Orthopsychiatry, $70,510-522$.

Smith, D. (1987). The everyday world as problematic: A feminist sociology. Boston, MA: Northeastern University.

Smith, D. (1996). Telling the truth after postmodernism. Symbolic Interaction, 19, 171-202.

Smith, B. (2000[1983]). Home girls: A Black feminist anthology. New Brunswick, NJ: Rutgers.

Stoppard, J. (2000). Understanding depression: Feminist social constructionist approaches. New York: Routledge.

Stoppard, J., \& Gammell, D. (2003). Situating sadness: Women and depression in social context. In J. Stoppard, \& L. McMullen (Eds.), Depressed women's treatment experiences: Exploring themes of medicalization and empowerment (pp. 39-61). New York, NY: New York University.

Taylor, J. M., Gilligan, C., \& Sullivan, A. (1996). Between voice and silence: Women and girls, race and relationship. Cambridge, MA: Harvard.

Thompkins, T. (2004). The real lives of strong Black women: Transcending myths, reclaiming joy. Chicago: Agate. Tolman, D. (1994). Doing desire: Adolescent girls'struggles for/with sexuality. Gender \& Society, 8, 324-342. Tolman, D. (2002). Dilemmas of desire: Teenage girls talk about sexuality. Cambridge, MA: Harvard.

Wallace, M. ([1978] 1990). Black macho and the myth of the superwoman. New York: Verso.

Ward, J. (1996). Raising resisters: The role of truth telling in the psychological development of African American girls. In B. Ross Leadbeater, \& N. Way (Eds.), Urban girls: Resisting stereotypes, creating identities (pp. 85-116). New York: New York University.

West, C., \& Zimmerman, D. (1987). Doing gender. Gender \& Society, 1, 125-151.

Williams, D. (2005). The health of U.S. racial and ethnic populations. Journals of Gerontology: Series B, $60 B, 53-62$.

Tamara Beauboeuf-Lafontant is Associate Professor of Sociology and Education Studies at DePauw University. Her current research focuses on constructions of racialized gender and their impact on women's bodies and overall health. She is working on a book entitled Costly Performances: Black Women, Voice, and the Embodiment of Strength. 